\title{
Applications of Open Source 3-D Printing on Small Farms
}

\author{
Joshua M. Pearce* \\ Department of Materials Science \& Engineering, Michigan Technological University, MI, USA; \\ E-Mail: pearce@mtu.edu; Tel.: +19064871466 \\ Department of Electrical \& Computer Engineering, Michigan Technological University, MI, USA
}

Submitted: 6 January 2015 | In revised form: 27 February 2015 | Accepted: 11 March 2015 |

Published: 16 April 2015

\begin{abstract}
There is growing evidence that low-cost open-source 3-D printers can reduce costs by enabling distributed manufacturing of substitutes for both specialty equipment and conventional mass-manufactured products. The rate of 3-D printable designs under open licenses is growing exponentially and there are already hundreds of designs applicable to small-scale organic farming. It has also been hypothesized that this technology could assist sustainable development in rural communities that rely on small-scale organic agriculture. To gauge the present utility of open-source 3-D printers in this organic farm context both in the developed and developing world, this paper reviews the current open-source designs available and evaluates the ability of low-cost 3-D printers to be effective at reducing the economic costs of farming. This study limits the evaluation of open-source 3-D printers to only the most-developed fused filament fabrication of the bioplastic polylactic acid (PLA). PLA is a strong biodegradable and recyclable thermoplastic appropriate for a range of representative products, which are grouped into five categories of prints: hand tools, food processing, animal management, water management and hydroponics. The advantages and shortcomings of applying 3-D printing to each technology are evaluated. The results show a generalizable technical viability and economic benefit to adopting open-source 3-D printing for any of the technologies, although the individual economic impact is highly dependent on needs and frequency of use on a specific farm. Capital costs of a 3-D printer may be saved from on-farm printing of a single advanced analytical instrument in a day or replacing hundreds of inexpensive products over a year. In order for the full potential of open-source 3-D printing to be realized to assist organic farm economic resiliency and self-sufficiency, future work is outlined in five core areas: designs of 3-D printable objects, 3-D printing materials, 3-D printers, software and 3-D printable repositories.
\end{abstract}

Keywords: 3-D printing; agricultural tools; distributed manufacturing; farm equipment; intensive agriculture; small farms

\section{Introduction}

World wide, the area of organic farmland continues to increase significantly [1,2]. Approximately a third of the world's organically managed land (i.e. 11 million hectares) is located in developing countries and nearly half of the world's organic producers are in Africa [2]. In the developing world in particular, these farms are owned by relatively resource-poor landholders. However, such small farms may contribute significantly to agricultural produc- 
tion, food security, rural poverty reduction and biodiversity conservation, despite the historic challenges small farmers face in terms of access to both productive resources and markets [3]. In addition, small farms in the developing world must overcome new challenges including adapting to climate change, market volatility and risks and vulnerabilities associated with integration into high-value chains [3-5]. There is some disagreement in the literature as to whether investments in infrastructure and technical efficiency alone are sufficient to address the negative impacts of climate change for developing-world farmers [6,7]. Although, it is clear that these challenges can at least in part be overcome by increasing the profit of organic farming in the developing world, which in turn is influenced by increasing revenue (e.g. by increasing yields, selling in more lucrative markets, etc.) or by reducing costs. Many organic farmers in both the developed and developing world save money and produce high-quality crops with few or no off-farm inputs, but most producers rely on at least some purchased inputs [8]. In addition, those farmers above the level of poverty subsistence also purchase their own equipment. As one of the costly inputs for organic agriculture is tools and equipment, this study investigates reducing farm-related tool costs for organic farms using opensource 3-D printing. In this way, distributed on-site manufacturing of tools and equipment can aid in organic farm self-sufficiency.

There is a growing body of evidence that low-cost opensource $3-D$ printers $[9,10]$ can reduce costs not only for high-end products like scientific equipment [11,12], but also for conventional mass-manufactured consumer goods [13-16]. There has been an explosion of open-source scientific equipment [12,17-22] and the number of free consumer designs has been rising exponentially [14]. There is also a body of work proposing that 3-D printers would also be useful for sustainable development [23-25]. While the application of 3-D printing in developing countries is still at an early stage, the technology application promises vast solutions to existing problems [23,24]. For example, most small farmers in the developing world use labor-intensive agricultural hand tools; Ishengoma and Mtaho hypothesize that superior tools can be developed with 3-D printing improving the efficiency of agriculture in the developing world [25]. At the same time it appears likely that the cost-saving nature of distributed manufacturing of 3-D printing could also benefit developed-world small-scale organic farms.

To gauge the current viability of the utility of opensource 3-D printers for organic farms both in the developed and developing world, this paper reviews the current opensource designs available and evaluates the ability of a lowcost 3-D printer capable only of fused filament fabrication (FFF) plastic manufacturing to reduce the cost of smallscale farming. A range of representative products are grouped into five categories of prints for review: 1) hand tools, 2) food processing, 3) animal management, 4) water management and 5) hydroponics. The advantages and shortcomings of each technology are evaluated. Conclu- sions are drawn on the economic potential of open-source 3-D printing in the organic farming context and future work is outlined to reach this potential.

\section{Methods}

\subsection{Equipment-MOST Delta RepRap}

Following lessons developed in free and open source software [26-30], the RepRap project has undergone a rapid technical evolution and offers the lowest cost 3-D printing equipment, which is also capable of printing its own replacement parts $[9,10,14,31,32]$. The early RepRaps used a Cartesian design, however, several RepRap 3-D printers now use delta robot designs similar to those used for pick and place in the electronics industry [33]. Delta RepRap 3-D printers have a stationary print bed and an extruder that moves in all 3 axes. The 3-D printer works by taking plastic filament into the extruder, melting it and depositing a 2-D pattern on the substrate. The extruder is then moved up a fraction of a mm (normally $0.1-0.35 \mathrm{~mm}$ ) and the next layer of the 3-D printed object is deposited. The process repeats until the entire object has been fabricated in solid plastic. Delta RepRap 3-D printers use standard AC electricity to run and while printing consume $<50 \mathrm{~W}$. In order to operate effectively this power should not be interrupted, the results of which will be discussed below.

Although delta 3-D printers are operationally less intuitive, they require less time and are easier to assemble, require fewer parts and have lower capital costs. The MOST (Michigan Tech Open Sustainability Lab) Delta RepRap has three linear actuators arranged vertically around a circle 1. The MOST Delta RepRap costs under $\$ 450$ in parts and can be built in approximately eight hours once the bill of materials (BOM) has been collected by inexperienced first-time 3-D printers [34,35] (the ability of new users to build working machines has been demonstrated over 100 times in a number of contexts from college classes to seminars and hack-a-thons). This type of 3-D printer was chosen for this study because of the value-it has low capital costs for the quality of the prints and the build volume (250 $\mathrm{mm}$ in radius and $270 \mathrm{~mm}$ high) provided. In addition, farmers, who are generally handy at fixing equipment, would best be served by a 3-D printer they could maintain themselves. Having access to a machine that they can take apart, fix, upgrade and try their own modifications on provides far more value at a significantly lower cost than a conventional tooling arrangement with warranties that simply may not be available in all parts of the world. In addition, such RepRap technology can contribute to farm self-sufficiency. All of the MOST Delta RepRap design files, schematics, build instructions and bill of materials are available on Appropedia for free [34]. The results of this study are not limited to this particular RepRap, however, all examples can be printed with it-and most other (full size) RepRap variants. 


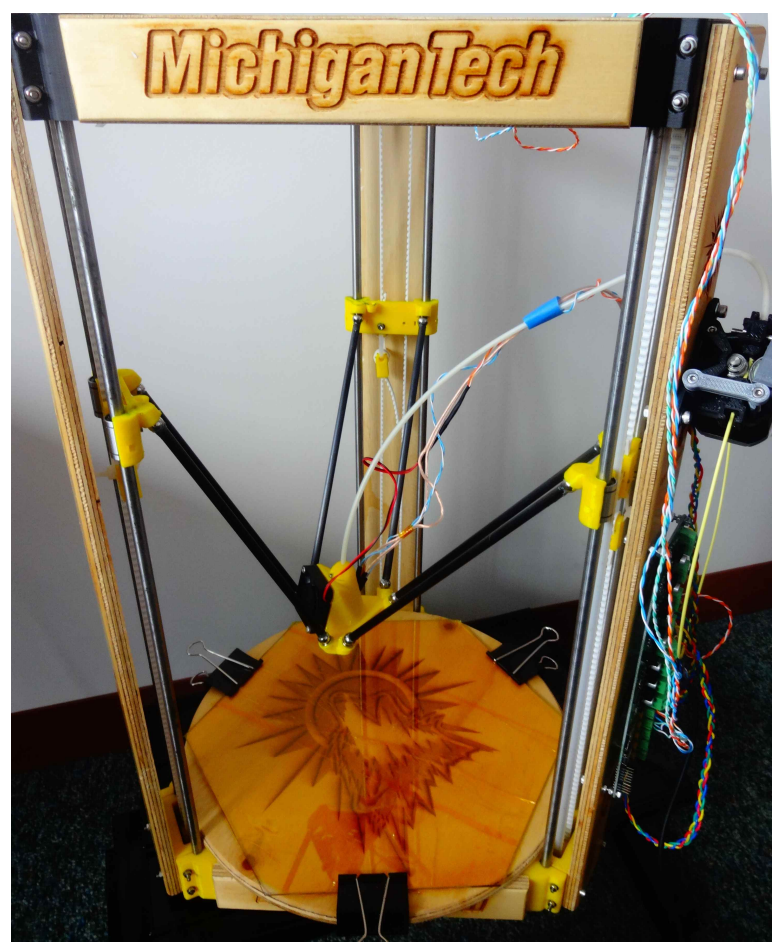

Figure 1. The MOST Delta RepRap 3-D printer. The yellow and black polymer components of the 3-D printer have been printed on the same type of 3-D printer. The glass hexagon at the base is print substrate.

\subsection{Free and Open-Source Software Tool Chain}

All of the software necessary to design and operate the 3-D printer is free and open source software that can be used for free (at no cost). For farmers wishing to minimize computing costs as well, older low-cost or 'junked' computers can be recycled into useful machines by installing a GNU/Linux [36] based operating system, such as Debian [37]. In addition, open-source computers such as the $\$ 35$ Raspberry Pi [38] can be attached to recycled peripherals to operate the 3-D printer.

3-D digital designs can be created by farmers themselves or customized from existing designs using OpenSCAD [39], which is a free and open-source script-based solid modeling program. OpenSCAD using parametric variables that automatically manipulate the entire part to enable simple modifications without the need for a deep knowledge in 3-D modeling. Farmers that are comfortable with basic geometry can create complex designs by manipulating primitive shapes (e.g. spheres, cubes, cylinders) in OpenSCAD, which then generates STL (STereoLithography) files of the finished parts, which are in turn sliced with the open-source Cura [40] before being printed (slicing is the software process of dividing a 3-D model into printable 2-D layers and it plots the toolpaths to fill them in). Parts that need structural strength are printed solid with $100 \%$ infill, while non-critical components can be printed with lower infill percentages, saving time, energy and plastic costs. Conventional RepRap firmware [41] or the new open-source Franklin printer firmware [42] was used on the printer itself and controlled with Printrun (open-source printer controller) [43].

\subsection{Materials-PLA}

RepRaps typically print in polylactic acid (PLA) or acrylonitrile butadiene styrene (ABS) for a wide range of colors. In this study, PLA will be evaluated as it is a stronger plastic than ABS; RepRap printed parts have an average tensile strength of $28.5 \mathrm{MPa}$ for ABS and 56.6 MPa for PLA [44]. PLA is a bio-based plastic, made up of a repeating chain of lactic acid. It is recyclable using conventional methods. In addition, PLA can be composted like other organic matter [45]. When composted, the moisture and heat in the compost pile break the PLA polymer chains apart, creating smaller polymer fragments, and finally, lactic acid. However, abiotic hydrolysis has been shown to be a rate limiting step in the biodegradation process of PLA and organisms were not able to accelerate depolymerization significantly by the action of their enzymes [46]. Both the smaller polymer fragments and lactic acid act as nutrients for microorganisms in the compost. As lactic acid is widely found in nature, a large number of organisms metabolize it into carbon dioxide, water and humus, an important component of soil fertility [47-50].

\subsection{Categorization of Printable Objects}

Utilizing the Appropedia wiki (appropedia.org)-is the largest collaborative site for solutions in sustainability, appropriate technology and poverty reduction - that curates many 3-D printing designs and Yeggi-a printable 3-D model search engine for tens of thousands of designs [51] - a range of 3-D printable objects that may be useful for organic farmers was identified and reviewed. For evaluation in this study, four products or product components were chosen in each of five categories: 1) hand tools, 2) food processing, 3) animal management, 4) water management and 5) hydroponics. The selected prints are summarized with their sources in Table 1. These twenty objects were chosen based upon i) having free and open source designs already available, ii) the ability to be printed on a low-cost MOST Delta RepRap using PLA while preserving their functionality, iii) having been previously demonstrated to be useful in farming and gardening (e.g. not models or toys) and iv) representing a variety of different types of functions for demonstration purposes. As such this is not a complete review of every 3-D printable object that may be useful for organic farmers, nor every object organic farmers may find value in printing, as there are literally thousands of these and the number of free designs is growing exponentially [14]. Rather, this study provides a survey of 3-D printing applications that represent classes of objects already designed and a realistic approach of how smallscale farmers could use available 3-D printers today. Thus, the objects included in Table 1 may also be useful to the broader general agriculture community as well. 
Table 1. Selected and categorized 3-D printable objects useful for organic farming.

\begin{tabular}{|c|c|c|c|c|}
\hline Hand Tools & Food Processing & Animal Management & Water Management & Hydroponics \\
\hline Triclaw apple picker [52] & Water tester [53] & Chicken feed holder[54] & Garden hose splitter [55] & 3DPonics [56] \\
\hline $\begin{array}{l}\text { Custom shovel handle } \\
\text { [57] }\end{array}$ & $\begin{array}{l}\text { Sausage funnels for } \\
\text { meat grinders [58] }\end{array}$ & Ant trap [59] & Gasket [60] & Hydroponic halo ring [61] \\
\hline Hand shovel [62] & Cassava press [63] & Field dressing tool [64] & $\begin{array}{l}\text { Contoured spigot for } 5 \\
\text { gallon bucket [65] }\end{array}$ & Hydroponic plant pot [66] \\
\hline Pulleys [67] & Corn sheller [68] & Gutting tool [69] & Irrigation stake [70] & Peristaltic pump [71] \\
\hline
\end{tabular}

\section{Results and Discussion}

\subsection{Hand Tools}

Many tools that may be useful for organic farmers are larger than the build volume of the MOST delta RepRap (a cylinder of $250 \mathrm{~mm}$ in radius and $270 \mathrm{~mm}$ high), yet can be created by it by printing individual components of the tool and then assembling them with non-printed, readily available components. An example of this is the tri-claw apple picker (Figure 2). The tool helps reduce labor in apple picking by eliminating the need to use a stepladder for high apples. The four-bar-linkage claw (Figure 2A) is closed by a sliding collar attached, by another four-bar, to each of the three fingers (Figure $2 \mathrm{~B}$ ). It is operated by pulling the cord visible in the lower right, which is knotted onto a sliding collar further down the pole. The collar is sprung to return the fingers to the open position. The apple picker print is threaded to fit a standard broom handle, which can be used when needed. For a longer pole, farmers can duct tape the broom handle to any pole that is physically manageable. The apple picker has several deficiencies however, that keep it from being as useful for the community as it potentially could be. It is licensed under the Creative Commons Attribution-Non-Commercial license. That means organic farmers can print and use it for their own use, but not sell it. Strictly speaking the CC-BY-NC license is not a true open source license [72]. In addition, only the STL files are shared, meaning farmers can print this version, but not easily make alterations (e.g. adjust fingers for optimal picking of other types of fruit). Finally, even if the source files had been shared, they were from an expensive professional closed-source CAD package ( $\$ 4,000$ to purchase and over $\$ 1,000$ per year for upgrades and support) that farmers are unlikely to have the time to develop the skill for, nor justify the budget for purchasing such a CAD software package.

Fortunately, there are several options for quality CAD software with shallow learning curves available as completely free and open-source software, such as OpenSCAD. OpenSCAD allows farmers to customize a design for their exact needs with minimal effort because of the script based parametric nature of OpenSCAD. OpenSCAD will be the primary solid modeling tool of choice for the majority of the designs presented below. For example, a customizable shovel handle (Figure 3 ) can be used as a replacement part for a broken shovel handle. In addition, it can be used on an existing tool with no handle to apply greater leverage, comfort and wrist relief, which prevents long-term injuries from repetitive motions (e.g. rotator cuff tears from digging). As farming tools have different diameters and farmers want different sized grips, depending on their hand sizes, all of the variables in the design are parametric. For example, at the start of the design, the code tells farmers how to change the diameter of the grip in clear documentation, which is currently set at $30 \mathrm{~mm}$ :

$$
G_{-} \text {Dia }=30 ; / / \text { diameter of Grip }
$$

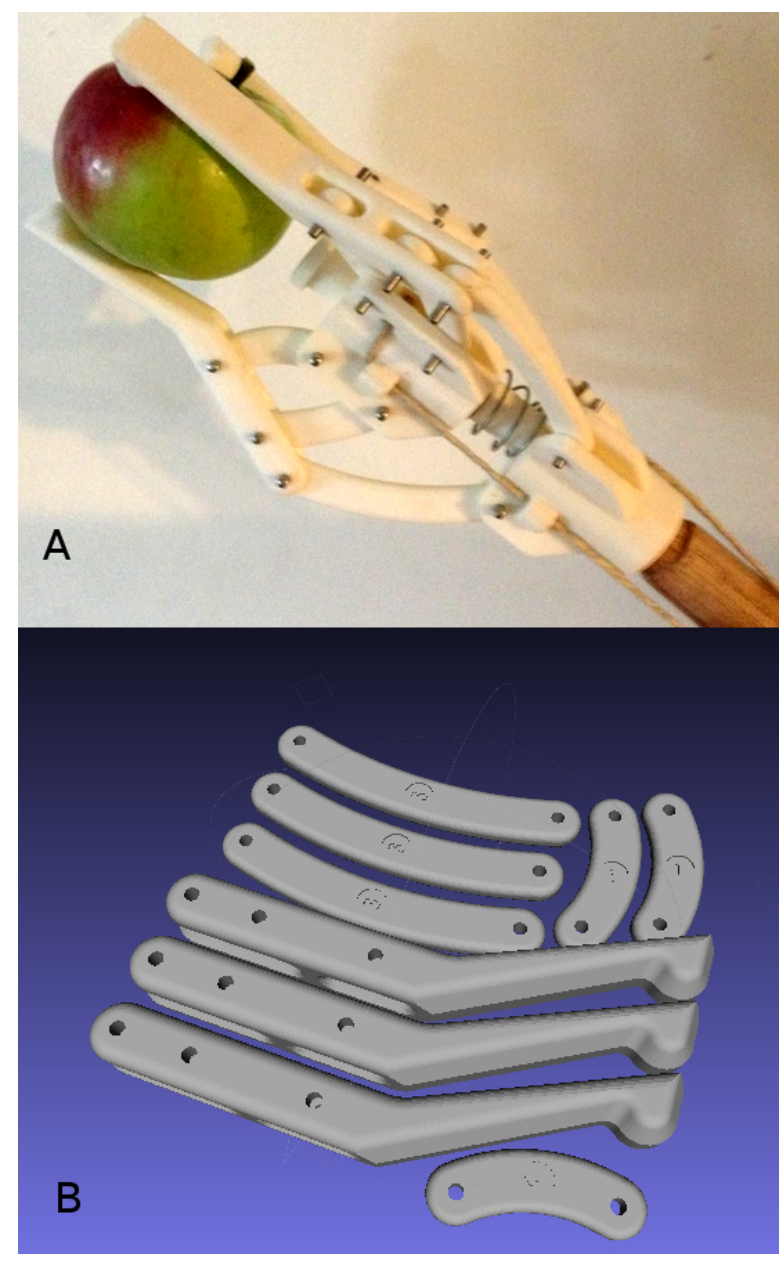

Figure 2. A) 3-D printed tri-claw apple picker grasping apple. B) the components of the claws. 
Simply by changing this one number the design can be customized for an individual farmer's grip preference. All of the mathematics to adjust the design have been preprogrammed to occur automatically. In addition, the number and placement of screw holes and also thickness and length of the section that overlap with the shovel can also be easily altered to user preference to obtain the required strength for a given application.

An un-modified RepRap normally only prints in one color at a time. However, it is possible to load in multiple colors of filament to improve aesthetics, enable artistic expression or use a company's logo colors during a print (Figure 3). Finally, the cost of the handle printed with commercial filament is less than a third of commercial plastic D-grip handles [57]. Being able to make custom products for a fraction of the cost of commercial products is a well established benefit of distributed manufacturing with 3-D printing [14]. It should be pointed out that this calculation does not involve any labor cost as, after the file is sent to the printer and even if the print itself takes hours, a welltuned 3-D printer does not require any human observation (e.g. the farmer can go about other tasks as usual and only go back to the printer to collect his finished product). For farms employing workers, time spent searching for free designs, customizing them, tweaking print settings and maintaining the 3-D printer would need to be included in any economic analysis.

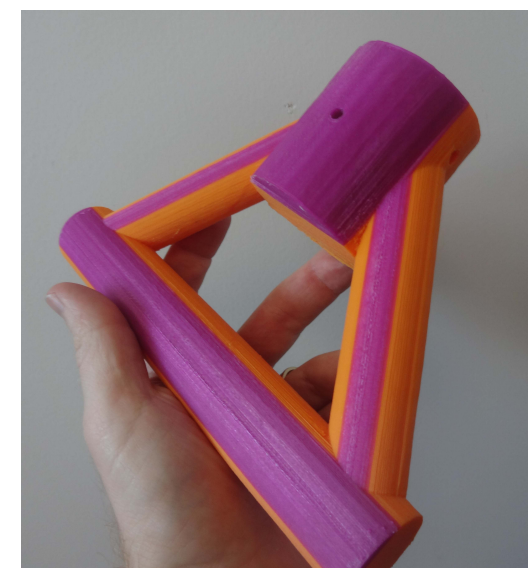

Figure 3. A 3-D printable customizable shovel handle in which the color of the filament had been switched during the print for cosmetic reasons.

Moving beyond only the handle, it is also possible to print an entire shovel (Figure 4). This shovel design enables printing handle components that fit together to extend the reach to the length a farmer requires. The mechanical strength of PLA [44] makes its use possible in tools that can bear a significant load if the parts are printed at $100 \%$ or with significant exterior thicknesses. This shovel could be used for light work-such as for adding to a compost pile, however, this shovel would not be appropriate for digging in hard soil. For such applications a metal tool is needed. Fortunately, an open-source 3-D printer capable of printing in steel and aluminum has been developed, which is essentially an upside-down MOST delta RepRap where the extruder is replaced with a gas metal arc welder [73]. Although there has been significant progress in turning the device into a tool for distributed manufacturing [74], it is still at an early stage of development and not ready for mass deployment.

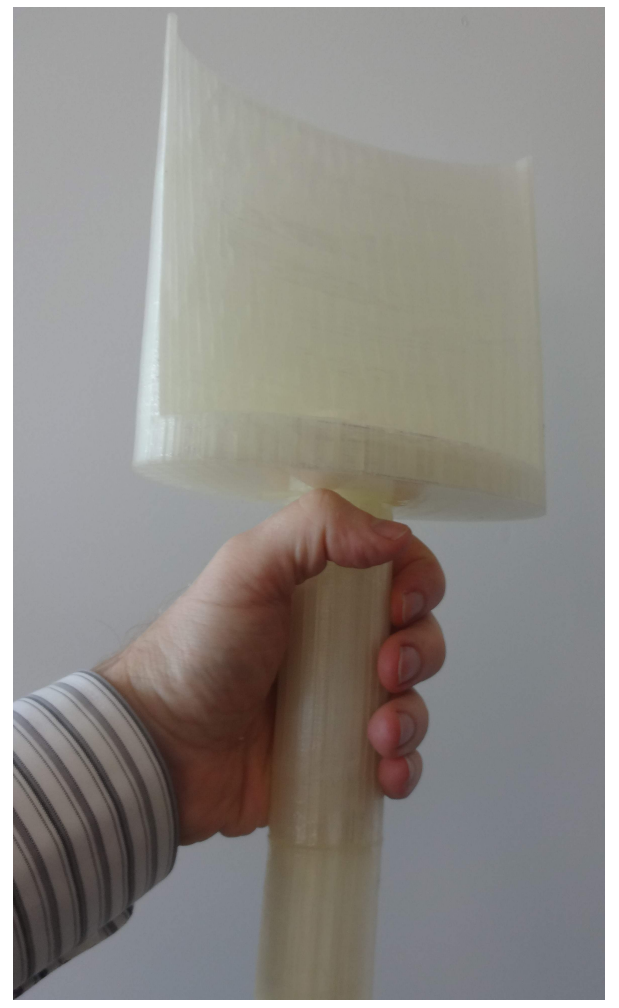

Figure 4. 3-D printable shovel with handle components that fit together to extend the reach to the necessary length.

Finally, another example of a tool that could be functional in plastic, but better suited to metal is the heavy-duty rope pulley (Figure 5). It can be used, for example, to raise water from a well or assist hay bale storage in a barn. As this is licensed under the default Appropedia license: CCBY-SA (creative commons license that demands attribution and that those that make derivatives share their work under the same license) it is a true open technology. Like the shovel handle, this pulley can be customized to any desired size by changing variables in the OpenSCAD script. It can also be paired with duplicates of itself to further increase mechanical advantage necessary for a given application.

\subsection{Food Processing}

Some of the 3-D printable equipment developed by the scientific community $[11,12]$ can also be useful on an organic farm, such as the open-source mobile water quality testing platform (Figure 6). This device, which uses printed components and off-the-shelf electronics, can perform colorimetry for biochemical oxygen demand/chemical oxygen 
demand and nephelometry to measure turbidity using ISO method 7027 [75]. Perhaps more interesting for farms on tight budgets, this approach has resulted in equipment that is as accurate, but costs between 7.5 and 15 times less than current commercially available tools [75]. This platform is currently under further development to add nitrate and phosphate quantification testing by coupling it with low-cost enzymes available from NECi that replace cadmium-based test kits.

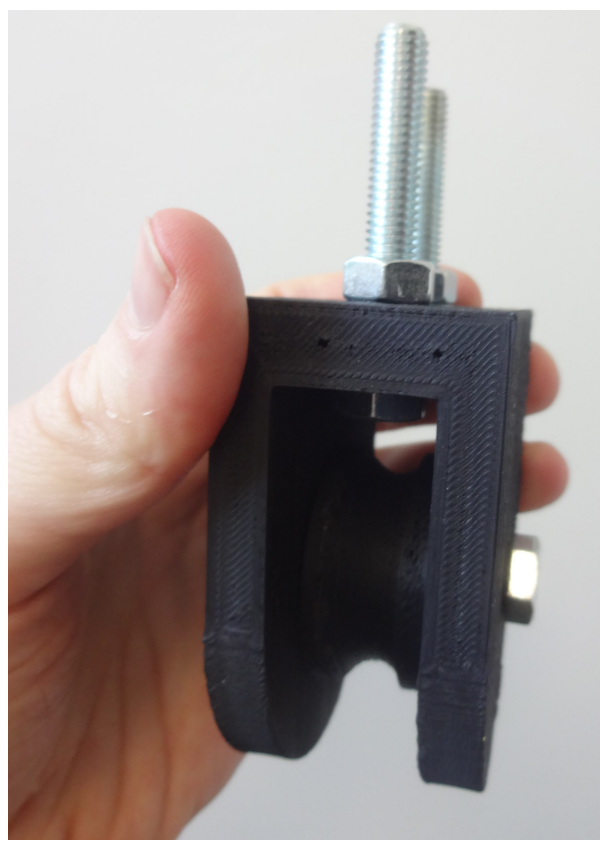

Figure 5. 3-D printable heavy-duty rope pulley.

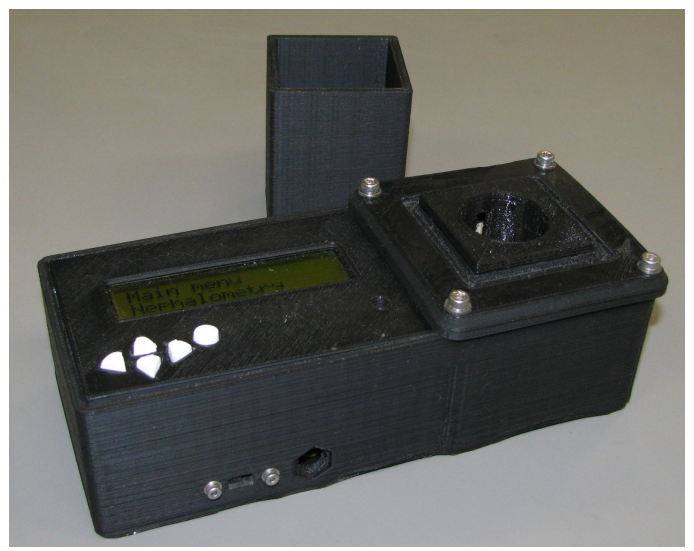

Figure 6. 3-D printable open-source mobile water quality testing platform capable of both colorimetry for biochemical oxygen demand/chemical oxygen demand and nephelometry.

In addition to expensive high-tech equipment, the use of an open-source 3-D printer makes fabricating simple tool additions, like sausage funnels for meat grinders easier (Figure 7). Other such funnels, like those used for canning can also be easily made with a 3-D printer although, depending on the application the type of plastic should be considered carefully. One of the primary reasons PLA is the dominant low-cost 3-D printer plastic is its relatively low melting point $\left(150^{\circ}-160^{\circ} \mathrm{C}\right)$ and glass transition temperature $\left(60^{\circ}-65^{\circ} \mathrm{C}\right)$. Thus, although virgin PLA can be foodgrade, PLA softens under some conditions of normal use for applications like canning. There are a variety of other 3-D printer filaments already available commercially including: ABS, nylon (e.g .Taulman 618), high-density polyethylene (HDPE) [76], Laywood [77], Laybrick [78], high impact polystyrene [79], PEEK [80], polyphenylsulfone [80], polyetherimide [80], polyoxymethylene [81], Polykey PLA HS [82], PLA HS NX [82], Polykey PPGF [82], PPMF [82], Polykey PA6GFV0 [82], polycarbonate and polyvinyl alcohol. For some of the high temperature filaments a different hot end on the RepRap is needed, but this does not increase the capital costs of the RepRap by more than a few tens of dollars. These alternative materials extend the range of useful 3-D printable farming applications.

However, PLA itself is quite versatile. Utilizing standard hardware and PLA 3-D prints, entire food presses can be manufactured. Consider a cassava press (Figure 8), which is a tool used in many parts of the developing world for increasing the longevity of food by pressing part, or all of the liquid out of the food. Although many cassava presses are large, this is an example of a household sized one. In addition, with minor design changes the press could be adapted for other uses or expanded to the printer diameter (up to $500 \mathrm{~mm}$ ).

According to the World Bank there are still over 1.2 billion people (approximately $20 \%$ of the world's population) that do not have access to electricity, almost all of whom live in developing countries [83]. Because of this, much of the automated food processing that is taken for granted in developed countries is still carried out by hand in the global south. For example, shelling corn (maize) is a chore done by hand in much of the rural developing world. For some time there have been commercial corn shellers that can save people hours of labor. However, maize comes in different sizes so different shellers are needed in different regions-and the various DIY shellers are a major task to fabricate. Using the OpenSCAD design code, corn shellers (Figure 9) can be customized for an exact location and corn type and 3-D printed in a short time. Various designs are possible, again by changing variables in clearly documented OpenSCAD scripts. All seven of the variables are shown below:

$$
\begin{aligned}
& h=55 ; / / \text { height of corn sheller } \\
& r t=35 ; / /[50: 130] / / \text { radius of top of corn sheller } \\
& r b=0.85 * r t ; / / \text { radius of bottom of corn sheller } \\
& \begin{array}{l}
d=6 ; / / \text { number of digits } \\
r=1.5 ; / / \text { digit radius } \\
l=1 ; / / \text { extra length of digit } \\
t=3 ; / / \text { thickness of sheller }
\end{array}
\end{aligned}
$$




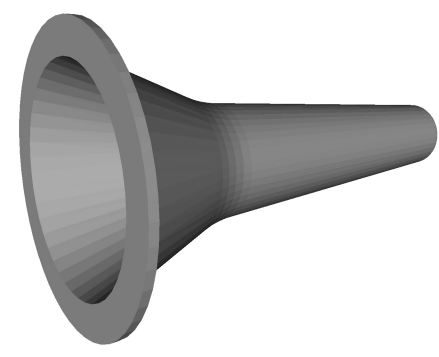

Figure 7. 3-D rendering of a 3-D printable sausage funnel.

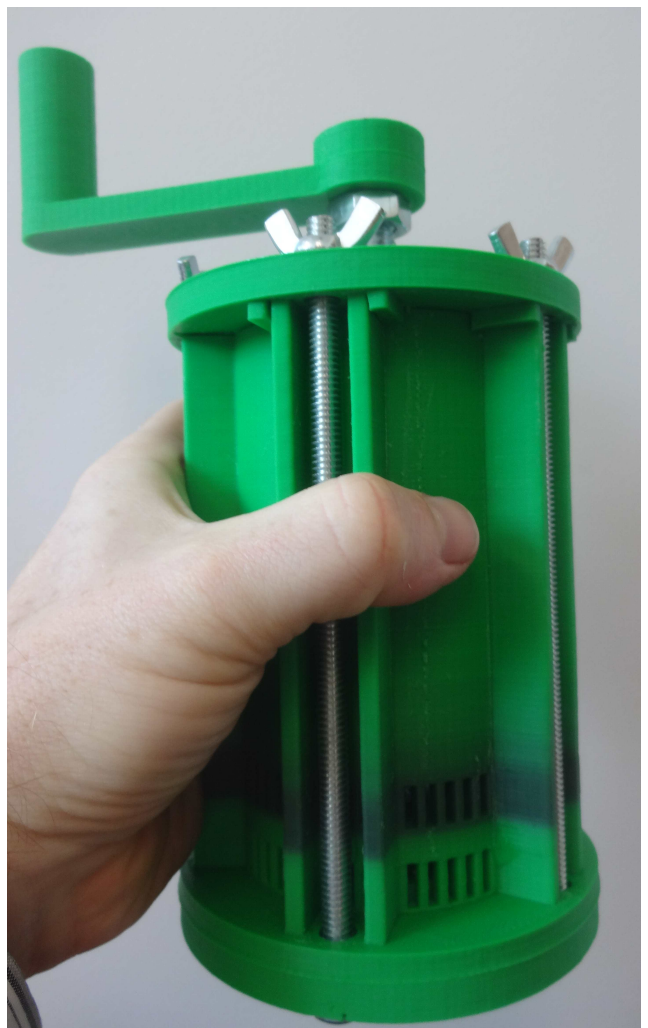

Figure 8. A 3-D printable a cassava press, which uses standard threaded rods and nuts.

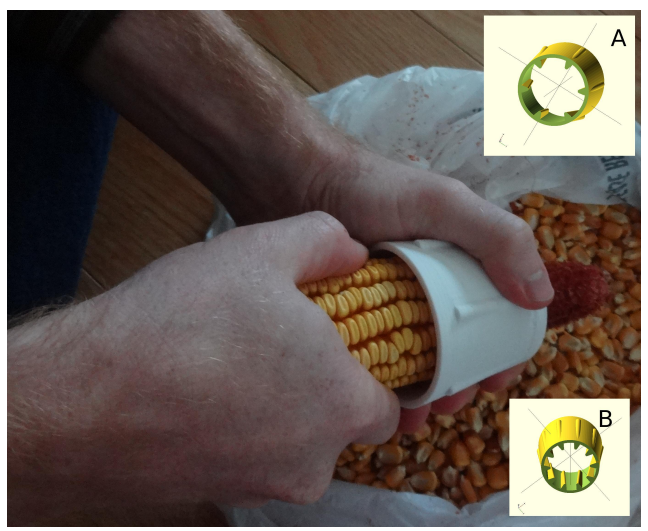

Figure 9. Corn being shelled with a 3-D printable corn sheller. Insets $\mathrm{A}$ and $\mathrm{B}$ demonstrate the ability to customize the OpenSCAD code to print corn shellers for different types of maize.

\subsection{Animal Management}

As the market for organic meat in the developed world has climbed in recent years there has been a significant increase in organic poultry farming in developing countries [84]. In addition to this, in the developing world, poultry farming is a popular project among small-scale organic farmers as the returns can be realized within a short period (approximately 1.5-2 months) [85]. Unfortunately, many of these projects fail due to disease outbreaks. Disease results in large numbers of poultry fatalities and poor production performance in both eggs and meat, which can cause financial losses to already poor farmers, and also increase human infection [86]. The majority of chicken diseases are transmitted through contaminated chicken waste. Appropriate chicken feed holders can help keep feed isolated from contaminated feces, minimizing outbreaks of disease. Thus, after corn is shelled using the print in section 3.2 then ground, it can be fed to chickens using 3-D printable chicken feed holders (Figure 10). This improves the economic viability of raising poultry by raising yield, but also reducing investment in treating sick birds.

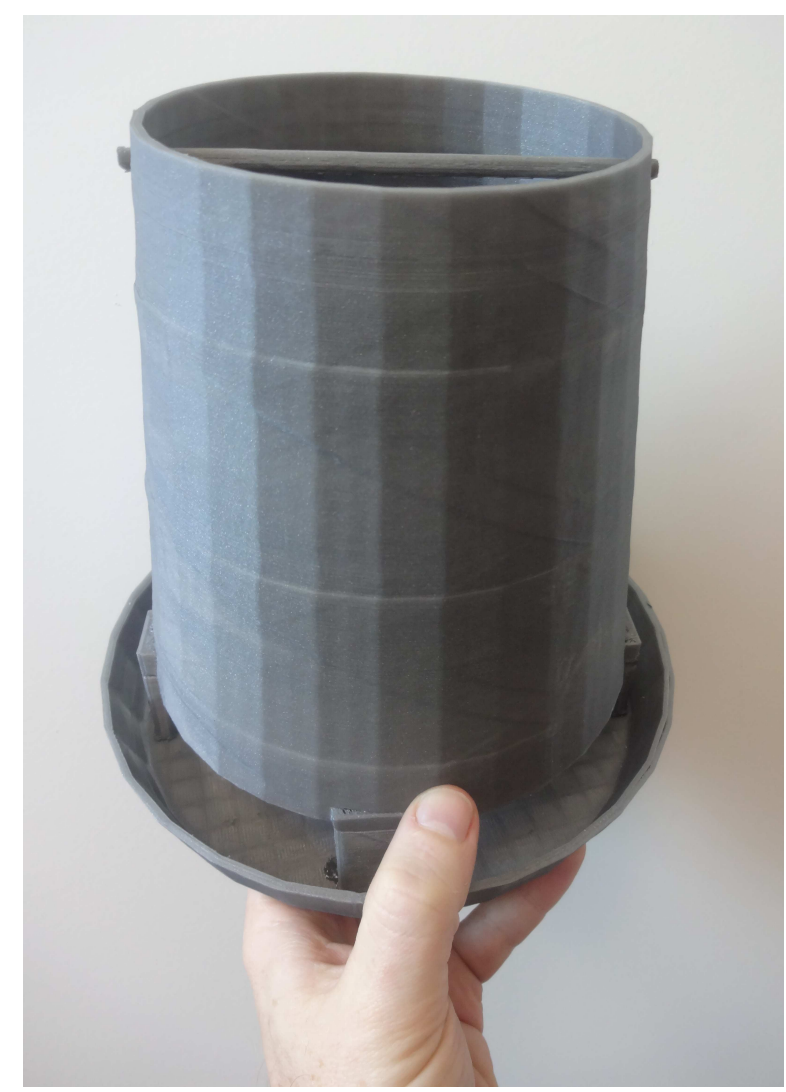

Figure 10. 3-D printable chicken feed holder.

3-D printing can also be used to make tools to eliminate unwanted animal pests. For example, a customizable OpenSCAD script can generate an ant trap (Figure 11). The trap can be baited with a mixture of borax and sugar to eliminate ants from an area. 


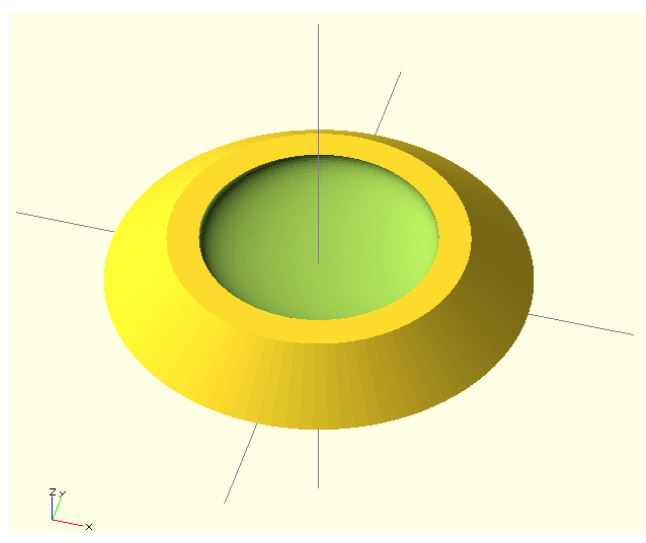

Figure 11. A customizable OpenSCAD rendering for an ant trap.

Finally, 3-D printed objects can be used for processing large animals. Animals raised on an organic farm, or harvested from the field on a small-scale, need to be field dressed and skinned in order to obtain high-quality, unspoiled meat. This process can be interrupted due to dull/blunt or improperly sized cutting blades. A dressing tool can be printed that mounts a replaceable and inexpensive utility blade on a 3-D printed handle with a guard (Figure 12). This tool enables the farmer to cut only what is needed in a safe manner as it allows cutting just beneath the skin without puncturing organs. The replaceable blade ensures ease of use and the lowest possible costs, while ensuring field dressing is faster and safer than with a traditional blade. Another example for this application is a tool used for gutting an animal (Figure 13). The tool is both customizable, so it can be sized appropriately for the animal being processed, and can be printed in its entirety. The tool is inserted into the animal's alimentary canal, twisted and pulled to remove a portion of the intestine, which can then be tied off and removed. This process eliminates the need for cutting around the area with a knife, making the field dressing process quicker, safer, and easier. Printing this tool cost far less than purchasing it commercially.

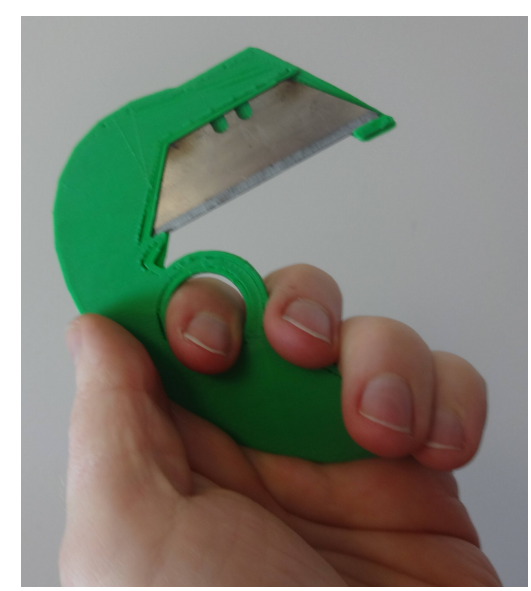

Figure 12. A dressing tool that mounts a replaceable utility blade on a 3-D printed handle with a guard.

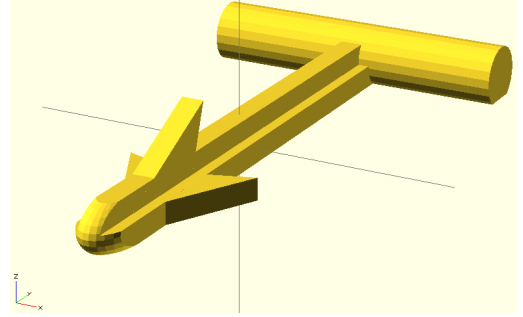

Figure 13. Tool for gutting an animal.

\subsection{Water Management}

A critical resource on many organic farms is water, and 3D printing components can help assist water management on a small farm. For example, an adapter (Figure 14) is used to split water streams from a common garden hose nozzle. The splitter can be customized to any desired size, and can be paired with duplicates of itself to enable the construction of complex irrigation systems. The purely PLA 3-D printed version, however, is likely to leak unless heat treated, which may not be acceptable for many farms. As PLA melts at low temperatures a quasi-permanent bond can be created by heating the metal hose end and then screwing it to the bottom of the adapter. This will deform the PLA, which will then form a watertight bond directly to the nozzle. In order to ensure a water tight seal that can be undone, a gasket is needed, either purchased or printed (Figure 15). Customizable gaskets can be directly printed using constrained extruder drivers printing elastomers such as 'ninjaflex' or using caulkstruders. A caulkstruder is an end effector that mounts any type of caulk and pushes it out in a controlled fashion like a syringe. This is a heavy device and cannot be mounted easily on the end effector of a delta 3-D printer. However, a recent innovation with the delta printer design turns the printer upsidedown such that the tool (caulkstruder) is fixed in place and the workpiece moves below it [87] (Figure 16). This convertible RepRap is capable of a long list of other functions including PCB milling, cutting, plotting, liquid handling, etc. using a collection of primarily $3-D$ printable magnet mountable hot-swap tool heads [87]. Thus, hundreds of gaskets can be printed from a single tube of caulk. These are more complex, less-tested machines that may be useful for organic farmers in the future. To enable gasket manufacturing on farm using only standard FFF printing in PLA, it is also possible to print a mold in PLA and fill it with silicone to produce silicone gaskets [88].

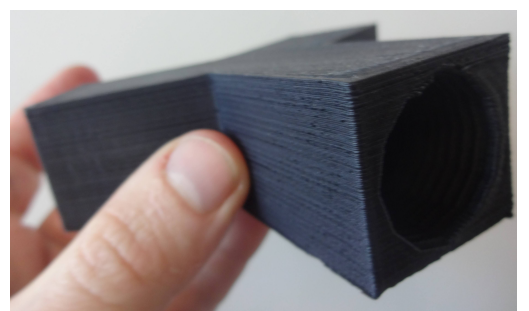

Figure 14. 3-D printable garden hose splitter. 


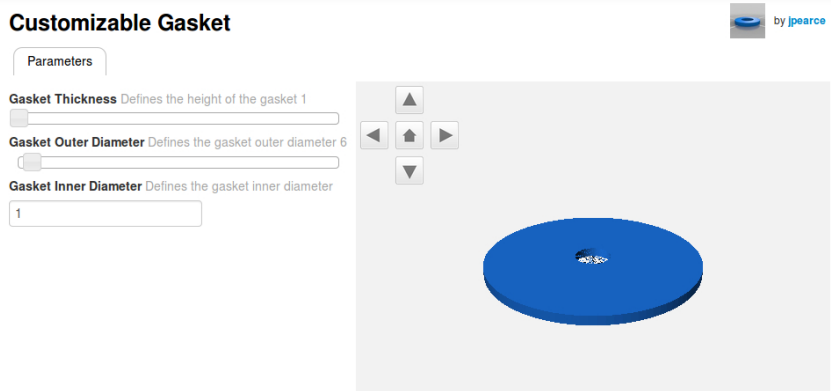

Figure 15. Customizable gasket design for use in 3-D printing.

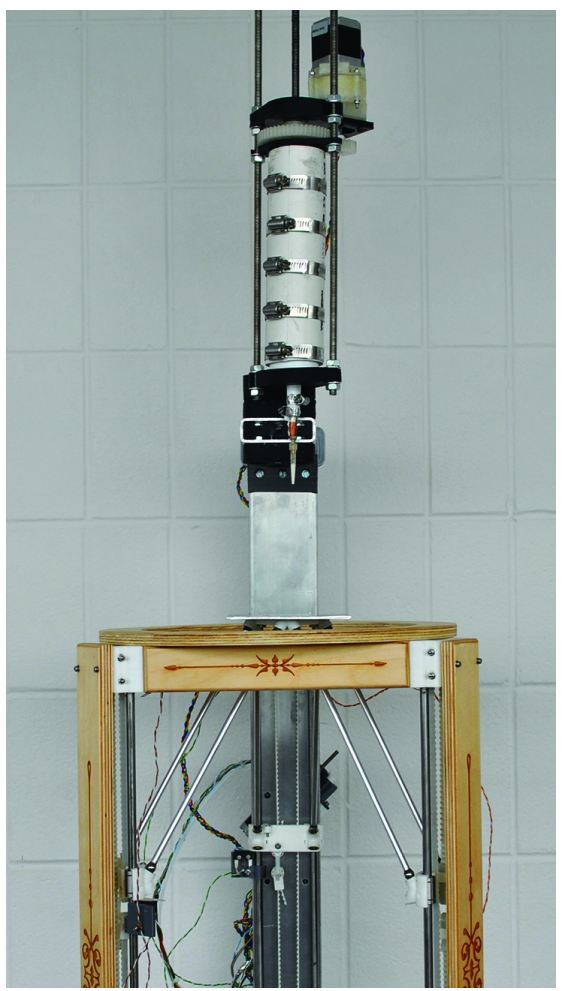

Figure 16. Upside-down delta 3-D printer with a stationary caulkstruder.

Gaskets made by either process are also useful for larger applications such as the contoured spigot for a five gallon bucket (Figure 17). Spigots manufactured for selfattachment typically rely on large gaskets to maintain a seal, which works with varying success on the curved surface of a bucket or barrel. By modeling a bucket with just its top and bottom diameters and its average thickness, it is easy to design a spigot with contours that fit the targeted water container and, with 3-D printing, a custom spigot attachment can be fabricated. The main attachment is reasonably easy to print and typical modification requires changing only four parameters in OpenSCAD. However, this design is also a good example of the generally unfinished nature of open-source design projects. Although the design of the connection is robust the spigot itself can be improved significantly.
It is relatively well established that organic farms can conserve water using a drip irrigation system, which allows for precise application of water into the root zones of targeted plants while minimizing runoff-related losses or deep percolation. Although savings are possible, many farmers use drip irrigation to improve their water use efficiencyimproving the yield for the amount of water used. The use of a drip irrigation system, whether in the developed or developing world, depends primarily on economics [89]. The following must be considered: the capital and labor costs of installing drip irrigation, costs and returns of production, and the price of and access to water. Farmers who use the technology may experience increased yields and higher income per unit of land as, depending on the crop, water applied under drip irrigation is approximately half as much as under flood irrigation. To optimize an irrigation system made up of any of the standard above-ground quarter-inch tubing that connects up to sprayers, drip feeds, and drop hoses, garden stakes (Figure 18) can be used. They are parametric and can be customized for the soil and watering conditions of any organic farm. There are many other water management related open-source 3-D printable designs, such as soil moisture sensors, watering can nozzles and spouts, liquid level sensors and rain water collection devices, including early work on different types of treadle pumps. Perhaps the most interesting progress is waterrelated 3-D printable designs, however, is in the more hightech area of hydroponics.

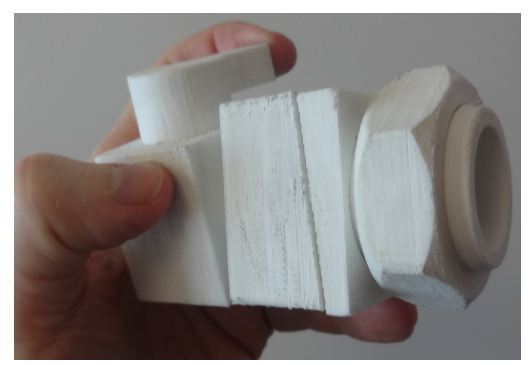

Figure 17. Contoured 3-D printable spigot for a five gallon bucket.

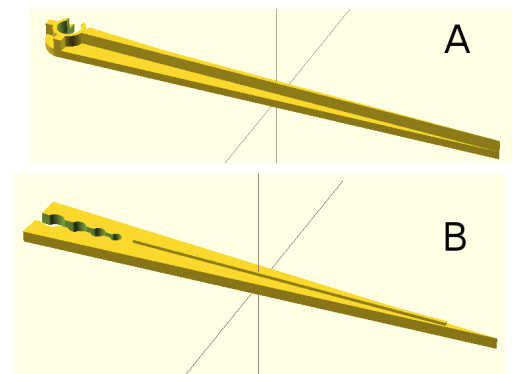

Figure 18. 3-D printable garden stakes used for irrigation systems made up of any of the standard above-ground quarter-inch tubing that connects to sprayers, drip feeds, and drop hoses. 


\subsection{Hydroponics}

Although a small research field in the early stages of development, it is possible to use hydroponic systems and still conform with organic principles [90] and philosophies by using i) nutrient solutions derived from acceptable organic sources, ii) biological pathogen control measures and iii) recirculating hydroponic systems [91-94]. Surprisingly, a study by Atkin and Nichols found organic hydroponics to be a more sustainable system of crop production than classical soil-based organic systems [95]. The environmental benefits of organic farming and food systems are well established [96]: they contribute to climate change mitigation [97] because of improved energy efficiency and biodiversity conservation [98-100]. In order to improve the environmental benefits of organic hydroponics even further, distributed manufacturing with open-source 3-D printers can be used as there is already evidence that it has a lower environmental impact than conventional manufacturing $[101,102]$.

For example, 3Dponics is a 3D-printable vertical hydroponics system (Figure 19) that re-uses $2 \mathrm{~L}$ bottles as growing platforms. An air pump collects nutrient solution from the bottom reservoir via a 3-D-printed conduit and pushes it through tubing to the top of the system where it drips out of a 3-D printed head into the chain of bottles until in returns to the reservoir to be reused in the next watering cycle (Figure 19A).

More conventional hydroponic system components can also be printed for a few cents and replace components that cost more than $\$ 10$, like a hydroponic halo ring (Figure 20). The pores in this device ensure that the containers are irrigated with water and nutrient solutions evenly. If used in conventional soil-based applications, three stakes can be added to the ring and it can be used for existing plants by slipping the stalk through the gap. Again the OpenSCAD code can be easily altered to fit any organic farming application or plant type (e.g. changing gap length for more mature plants). There are also several different versions of hydroponic plant pots (Figure 21). Again, a farmer can evolve the open-source design for his specific application and print it for lower costs than purchasing from a conventional supplier. Finally a more complex version of a peristaltic pump (Figure 22), which can be used to pump the water nutrient solution for hydroponics. Peristaltic pumps work off a single motor and have the advantage of fluid never coming into contact with mechanical parts of the machine as it is contained within a flexible tube (Figure 22). As peristaltic pumps have several uses, including as 3-D printer extruders, there are many different designs already freely shared under open-source licenses.

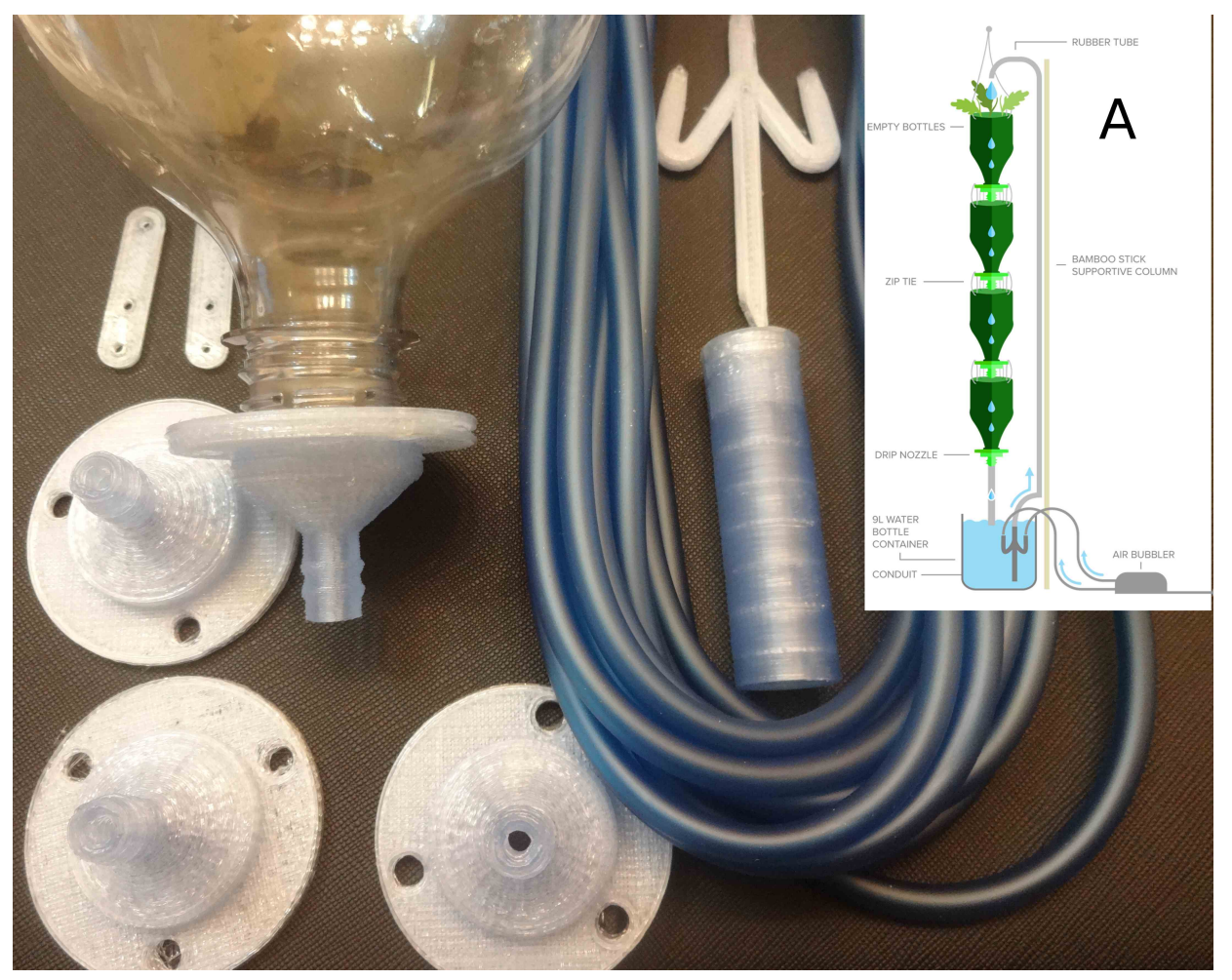

Figure 19. A) Shows a schematic of the 3Dponics system, which is a 3-D printed hydroponics systems that uses discarded $2 \mathrm{~L}$ bottles as growing platforms. The digital image shows the primary 3-D printed components and rubber tubing used for the system. 


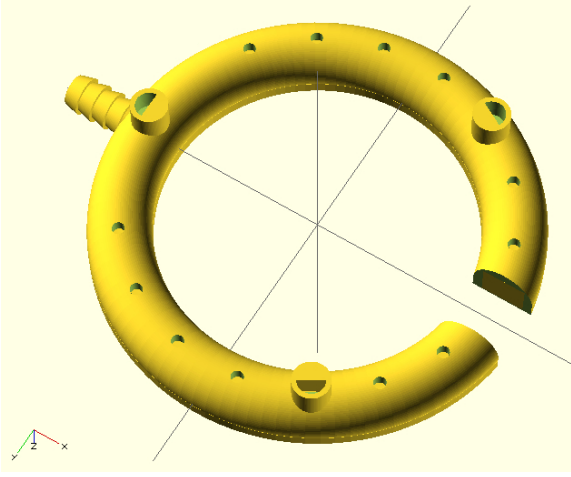

Figure 20. A rendering in OpenSCAD of a customizable 3-D printable hydroponic halo ring.

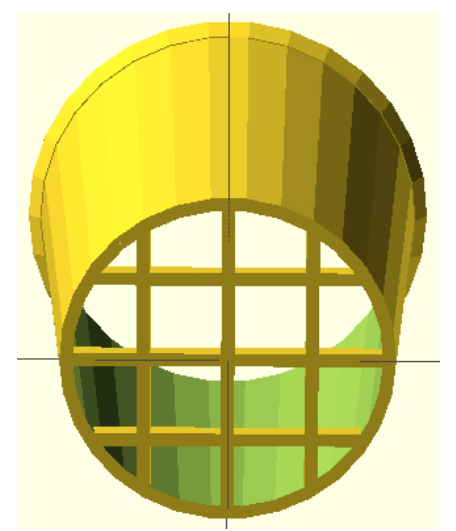

Figure 21. A rendering in OpenSCAD of a customizable 3-D printable hydroponic plant pot.

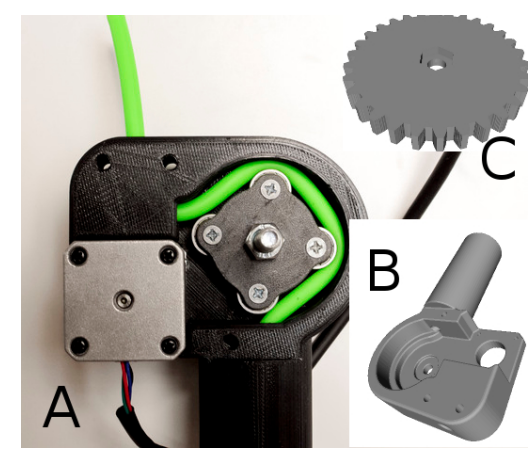

Figure 22. A) a 3-D printable peristaltic pump, B) a rendering of the printable housing and $\mathrm{C}$ ) a rendering of the printable gear.

\subsection{Economics}

Most of the preceding examples of PLA 3-D printable designs offer advantages in regards to customization of equipment for organic farmers, and this has a value, although it is difficult to quantify. However, all of them offer direct cost advantages over purchasing commercial equivalents. This economic advantage mirrors past analysis that looked at more generic consumer products [14]. In all of the preceding cases it was assumed that virgin commercial PLA filament was purchased and average U.S. electricity rates were used. In general, these assumptions enable a RepRap to print products for much lower costs than what is available commercially, even if shipping and taxes are ignored.

This already substantial economic advantage of RepRap-based distributed manufacturing increases by a factor of ten when recyclebots [103] (waste plastic extruders) are used to produce the 3-D printer filament. Recyclebots of various designs are now being developed and commercially distributed, allowing filament production from either virgin or recycled material, including the Lyman extruder [104], Filastruder [105], FilaFab [106], Filabot [107], EWE [108], ExtrusionBot [109], and the Strooder [110]. Such recyclebots can produce 3-D printer filament out of PLA from virgin PLA pellets, which decreases the cost of filament from $\$ 20-50 \mathrm{~kg}^{-1}$ for commercial filament to $\$ 6$ $\mathrm{kg}^{-1}$. If post-consumer PLA is collected and used to make filament, the energy costs are only about US $\$ 0.10 \mathrm{~kg}^{-1}$ [103]. Similarly, other plastics can be used with similar material costs. For example, $1 \mathrm{~kg}$ of printable HDPE filament can be generated from 20 discarded milk jugs that and uses only US $\$ 0.10$ of electricity [103], but more care must be taken with using it for printing. Again, these costs do not include labor. However, use of recyclebots results in such substantial savings, even when labor costs are taken into account, the technology provides a new method of poverty reduction, as waste pickers can gain access to a much greater income from their labor [111]. In addition, there is now substantial evidence from life cycle analysisbased studies that distributed recycling has a significant environmental benefit over traditional centralized recycling [112,113].

If the capital cost of the RepRap 3-D printer is not included, it is clear that distributed manufacturing of equipment for organic farms on site is economically advantageous. It is less clear, even with the widespread selection of existing free designs (of which only a small fraction have been discussed in this article), that a 3-D printer could economically justify the purchase price for organic farm applications alone, as such economics is heavily dependent on the use of the printer [14]. Although a single water testing platform (Figure 6) pays for the entire 3-D printer 4-8 times over, hundreds of irrigation stakes (Figure 18) would need to be printed to cover the capital costs of the 3-D printer. It is obviously also much easier to justify the capital cost of the printer if a recyclebot is available either on farm in or locally. Each organic farmer would need to evaluate his own potential use based on his applications and needs. It is likely that there could be one or several highly utilized products or components that would economically justify purchasing the 3-D printer, and then the other products it manufactured would simply be extra side benefits adding to the profitability of the investment.

As the technological evolution of open-source RepRap 3-D printing continues to reduce costs, improve reliability, 
resolution and speed and both the number and assumed utility of open-source designs continues growing exponentially [14], open-source 3-D printers could create what is claimed to be a third industrial revolution [114,115]. It appears prudent for organic farmers to realize this opportunity if the savings from self-sufficient farm-manufacturing with 3-D printers meets their minimum acceptable rate of return as the savings are likely to be greater in the future than any return calculated at a given time. This is primarily due to the open source nature of the technologies as future improvements of both the printers and the designs can be accessed for free.

\section{Future Work}

Although there is considerable evidence that organic food can help provide food security to an increasing global population [116-118], in many contexts the costs of organic food must continue to decline [119-125]. It is clear the open-source $3-D$ printing can contribute to this goal, but there is substantial future work needed in the area of distributed 3-D printing and agriculture before it can be said to be an open source appropriate technology (OSAT) [126] ready for scaling to drive sustainable development over the entire world [127]. Areas that need further investigation include improvements in: 1) designs of 3-D printable objects, 2) materials, 3) 3-D printers, 4) software and 5) 3-D printable repositories.

Although there are thousands of 3-D printable designs, of which only a few have been reviewed here, they still only represent a small fraction of the number of components and products that could be replaced with farm-fabricated equipment. The number of free designs is growing daily, but there is still more design work needed before organic farmers have access to a free catalog of designs covering all their equipment needs. Many of the existing designs are little more than prototypes, having been designed, printed and tested by a single individual. As the global sharing economy [128-131], P2P (peer to peer) economy $[132,133]$ and the hacker ethic [134] behind it continue to grow, more designs, improved designs (e.g. optimized for printability, conservation of materials and energy, etc.) and mass-tested designs will make their way onto the Internet. There is a large number of opportunities for 3-D printable designs relevant to organic farmers. For example, many other insect traps than the single example shown here, which are discussed by Shimoda and Honda are also 3D printable [135].

Next, more work is needed in the area of materials development and testing for 3-D printing applications on the farm. PLA is a good printing material, but considerably more work is needed on longevity under farm conditions (e.g. UV radiation tolerance compared to other polymers [136,137], mechanical strength under repeated loading conditions, degradation rates while exposed to water, etc.). PLA must also be tested under repeated recycling cycles using industrial and recyclebot technology to deter- mine the extent of the deterioration of the properties as a function of cycle number and the need to introduce virgin PLA into the mix to maintain adequate material properties. Ideally PLA could be produced from organic agricultural waste on site on a farm, and the small scale OSAT needed to do this has yet to be developed. In addition to PLA, other polymers and other materials, including composites, must become as developed as PLA already has for widespread use. Care should be taken to ensure compatibility with an organic farm so that harmful substances are avoided through the entire life cycle of the material [138].

The technological evolution of the 3-D printers themselves has been rapid, but further improvements in RepRap design will allow for: 1) less complex designs with fewer parts, 2) easier and faster assembly and repair, 3) increased reliability, 4) lower capital costs, 5) faster printing, 6) higher resolution, 7) more consistent properties in printed objects, 8) higher percentages of printable components (until $100 \%$ is reached), 9) higher energy efficiency, 10) multi-material and variable material printing and 11) quieter printing. All of these goals are being actively worked on by the international RepRap community, consisting of hundreds of professional scientists, engineers and makers, tinkers, and amateur hobbyists. Each incremental improvement made is shared and dispersed throughout the world, thereby improving the capabilities of organic farmers that adopt the technologies as many 3-D printer upgrades can simply be downloaded, printed and installed on the machine that made them.

One area of RepRap development that is of particular interest to the organic farming community in isolated regions of the developing world is the recent demonstration of several types of solar photovoltaic (PV) powered 3-D printers [138]. These printers can operate literally in the field and thus offer advantages for mobility, as well as use by off-grid organic farmers. When printing using most types of firmware, loss of power represents a catastrophic print failure as the chain of g-code is lost and it is extremely difficult to find the exact location of a failure when the 3$D$ printer is operating without observation. Normally 3-D printers are operated without continuous user observation for areas with reliable grid power. There is some early development on passive monitoring with web-cams, but at this point, for reliable printing in areas with frequent grid power interruptions some form of electrical power storage is necessary for critical prints, which is designed into to the PV-powered RepRap designs. It should be noted that although Franklin firmware [42] can recover from power failure, which can alleviate this problem somewhat, the pause in the printing process could also effect the mechanical integrity of the part because of the effects of a pause on the solidification process. Additional work is needed to further reduce the cost and reliability of this class of self-powered RepRap systems.

Improvements in the software tool chain will not only improve the ease of use of 3-D printers for farmers and other non-specialists, but also improve performance. Sim- 
ple 'print' buttons need to be integrated into all popular open-source solid modeling programs (e.g. Blender, OpenSCAD, and FreeCAD) with the necessary code to ensure quality prints on individual machines, just as standard 2-D printing operates today. Improvements in the firmware and integration of the modeler/viewer, slicer and printer controller are all needed. Auto-calibration, self-leveling, error and failed print detection and recovery will all enable a more plug-and-play experience for non-3-D printer experts. Slicers need to be improved to enable fill pattern and density optimization based on finite element analysis of printed components under realistic loads. In addition, printing support must be improved to minimize filament use, time and energy printing and part clean up while ensuring geometric integrity. Further, printer settings including material selection must be optimized in real time for the specific geometries of a given print.

Finally, the free repositories that store 3-D printable files (e.g. Youmagine, Libre3D, etc.) must all be improved. This can be done by improving search, tagging, licensing, easing the uploading of derivatives, and integrating OpenSCAD customizers in addition to STL renderers. The repositories need to go beyond simply storing STLs or even OpenSCAD code and begin to store information about optimal slicing, control and materials. Printed components need to be vetted and tested in a way that enables greater confidence in the printer that the print will perform as intended. This information can all be shared in a way to enable innovation [139] and further sustainable development for everyone. In some cases it will be necessary for independent labs and government agencies to provide this form of testing and approval, but in other cases the solutions can be crowd-sourced [140,140-143]. For example,

\section{References}

[1] Willer H, Lernoud J. Organic Agriculture Worldwide: Key results from the FiBL-IFOAM survey on organic agriculture worldwide 2013. Available from: http: //orgprints.org/22349/.

[2] Willer H, Kilcher L. The world of organic agriculture: statistics and emerging trends 2009. Available from: http://orgprints.org/18380/16/willerkilcher-2009.pdf.

[3] Thapa G, Gaiha R. Smallholder farming in Asia and the Pacific: Challenges and Opportunities. IFAD conference on New Directions for Smallholder Agriculture; 2014.

[4] de Janvry A, Frisvold G, Murgai R, Sadoulet E, Winters P. Economic and Welfare Impacts of Climate Change on Developing Countries. Environmental and Resource Economics. 1998;12(1):1-24.

[5] Rodriguez N, Seo K. Land Grab, Food Security and Climate Change: A vicious circle in the Global South. In: Chhetri N, editor. Human and Social Dimensions of Climate Change. InTech; 2012. p. cabbage white butterflies are known to be antisocial when they are laying their eggs, so if decoy butterflies [144] are printed, it can be hypothesized that they might reduce pest damage in cabbage crops. The number of variations on such an experiment that 3-D printing affords is substantial (e.g. shape, size, type, density etc.) so a crowd sourced experiment could be helpful for developing an inexpensive 3-D printed solution to this crop pest.

\section{Conclusions}

The results of this review show a generalizable technical viability and economic benefit for adopting open-source 3-D printing for any of the organic farm technologies reviewed, although the individual economic impact is highly dependent on needs and frequency of use on a specific farm. Despite liming the applications of open-source 3-D printing to only the most-developed fused filament fabrication of the bioplastic polylactic acid, five categories of prints : 1) hand tools, 2) food processing, 3) animal management, 4) water management and 5) hydroponics were all found to be technically viable. PLA is a strong biodegradable and recyclable thermoplastic appropriate for use on an organic farm. Capital costs of an open-source 3-D printer can be saved with the on-farm printing of a single advanced analytical instrument in a day or replacing of hundreds of inexpensive products over a year. In order for the full potential of open-source 3-D printing to be realized to assist organic farm economic resiliency and self-sufficiency, future work is outlined in five core areas: designs of 3-D printable objects, 3-D printing materials, 3-D printers, software and 3-D printable repositories.

$$
\text { 165-180. }
$$

[6] Nelson G, Rosegrant M. The Costs of Agricultural Adaptation to Climate Change. Available from: http://siteresources.worldbank.org/EXTCC/ Resources/407863-1229101582229/D\&CCDP_4Agriculture9-15-10.pdf.

[7] Below TB, Mutabazi KD, Kirschke D, Franke C, Sieber S, Siebert R, et al. Can farmers' adaptation to climate change be explained by socio-economic household-level variables? Global Environmental Change. 2012;22(1):223-235.

[8] Andrews N, Baker B, Riddle J. Can I use this input on my organic farm? Eorganic. Available from: http://www.extension.org/pages/18321/can-i-usethis-input-on-my-organic-farm\#.VJCgD61J1As.

[9] Bailard S, Bowyer A, Olliver V, Sells E, Smith Z. RepRap: The Replicating Rapid Prototyper: Maximizing Customizability by Breeding the Means of Production. In: Piller FT, Tseng MM, editors. Handbook of Research in Mass Customization and Personalization: Strategies and concepts. World Scientific; 2009. p. 568-580. 
[10] Jones R, Haufe P, Sells E, Iravani P, Olliver V, Palmer C, et al. RepRap - the replicating rapid prototyper. Robotica. 2011 January;29(01):177-191.

[11] Pearce JM. Building Research Equipment with Free, Open-Source Hardware. Science. 2012;337(6100):1303-1304.

[12] Pearce J. Open-source lab: How to build your own hardware and reduce research costs. New York, NY, USA: Elsevier; 2013.

[13] Bradshaw S, Bowyer A, Haufe P. The intellectual property implications of low-cost 3D printing. ScriptEd. 2010;7(1):5-31.

[14] Wittbrodt BT, Glover AG, Laureto J, Anzalone GC, Oppliger D, Irwin JL, et al. Life-cycle economic analysis of distributed manufacturing with open-source 3-D printers. Mechatronics. 2013;23(6):713-726.

[15] Gershenfeld N. Fab: The Coming Revolution on Your Desktop-from Personal Computers to Personal Fabrication. New York, NY, USA: Basic Books; 2007. Available from: http://www.amazon.com/exec/obidos/redirect? tag=citeulike07-20\&path=ASIN/0465027466.

[16] Wohlers T, Caffrey T. Annual Worldwide Progress Report. Fort Collins, CO, USA: Wohlers Associates, Inc.; 2014.

[17] Carvalho MC, Eyre BD. A low cost, easy to build, portable, and universal autosampler for liquids. Methods in Oceanography. 2013;8(1):23-32.

[18] Wijnen B, Hunt EJ, Anzalone GC, Pearce JM. OpenSource Syringe Pump Library. PLoS ONE. 2014 09;9(9):e107216.

[19] Zhang C, Anzalone NC, Faria RP, Pearce JM. OpenSource 3D-Printable Optics Equipment. PLoS ONE. 2013 03;8(3):e59840.

[20] Sulkin MS, Widder E, Shao CC, Holzem KM, Gloschat C, Gutbrod SR, et al. 3D Printing Physiology Laboratory Technology. American Journal of Physiology - Heart and Circulatory Physiology. 2013;305(11):H1569-H1573.

[21] Gildea K, Milburn N. Open-source products for a lighting experiment device. Behavior Research Methods. 2014;46(4):960-983.

[22] Kelley CD, Krolick A, Brunner L, Burklund A, Kahn D, Ball WP, et al. An Affordable Open-Source Turbidimeter. Sensors. 2014;14(4):7142-7155.

[23] Pearce J, Blair CM, Laciak K, Andrews R, Nosrat A, Zelenika-Zovko I. 3-D Printing of Open Source Appropriate Technologies for Self-Directed Sustainable Development. Journal of Sustainable Development. 2010;3(4):17-29.

[24] Birtchnell T, Hoyle W. 3D Printing for Development in the Global South: The 3D4D Challenge. London, UK: Palgrave Macmillan; 2014.

[25] Ishengoma FR, Mtaho AB. 3D Printing: Developing Countries Perspectives. CoRR. 2014;abs/1410.5349. Available from: http://arxiv.org/abs/1410.5349.
[26] Raymond E. The cathedral and the bazaar. Knowledge, Technology \& Policy. 1999;12(3):23-49.

[27] Lakhani K, von Hippel E. How Open Source software works: "Free" user-to-user assistance. Research Policy. 2000;32:923-943.

[28] Lakhani K, Wolf R. In: Feller J, Fitzgerald B, Hissam S, Lakhani K, editors. Why Hackers Do What They Do: Understanding Motivation and Effort in Free/Open Source Software Projects. Cambridge, MA, USA: MIT Press; 2005. p. 1-27.

[29] Hippel Ev, Krogh Gv. Open Source Software and the "Private-Collective" Innovation Model: Issues for Organization Science. Organization Science. 2003;14(2):209-223.

[30] Hars A. Working for Free? Motivations for Participating in Open-Source Projects. International Journal of Electronic Commerce. 2002;6:25-39.

[31] Chulilla JL. The Cambrian Explosion of Popular 3D Printing. International Journal of Interactive Multimedia and Artificial Intelligence. 2011;1(4):30-32.

[32] Kentzer J, Koch B, Thiim M, Jones RW, Villumsen E. An open source hardware-based mechatronics project: The replicating rapid 3-D printer. In: $4^{\text {th }}$ International Conference on Mechatronics (ICOM); 2011. p. 1-8.

[33] Rocholl JC. Rostock. 2012. Available from: http: //reprap.org/wiki/Rostock.

[34] Delta Build Overview: MOST. Available from: http: //www.appropedia.org/Delta_Build_Overview:MOST.

[35] Irwin JL, Pearce JM, Anzolone G, Oppliger DE. The RepRap 3-D Printer Revolution in STEM Education. In: $121^{\text {st }}$ ASEE Annual Conference \& Exposition;. .

[36] Linux.com. Linux Distributions. Available from: http: //www.linux.com/directory/Distributions.

[37] Software in the Public Interest, Inc. Debian - The universal operating system. Available from: https: //www.debian.org/.

[38] Raspberry Pi Foundation. Available from: http:// www.raspberrypi.org/.

[39] OpenSCAD - The Programmers Solid 3D CAD Modeller. Available from: http://www.openscad.org/.

[40] Ultimaker. Cura. Available from: http://wiki.ultimaker. com/Cura.

[41] RepRap. List of Firmware. Available from: http:// reprap.org/wiki/List_of_Firmware.

[42] Wijnen B, Anzalone G, Haselhuhn A, Sanders P, and Pearce J. Free and Open-source Control Software for 3-D Motion and Processing. Unpublished.

[43] Yanev K. Printrun. Available from: http://www. pronterface.com/.

[44] Tymrak BM, Kreiger M, Pearce JM. Mechanical properties of components fabricated with opensource 3-D printers under realistic environmental conditions. Materials \& Design. 2014;8(1):242-246.

[45] NatureWorks LLC. Ingeo Biopolymer 4043D Technical Data Sheet Yanev K. Available from: http://www.natureworksllc.com/ /media/ 
Technical_Resources/Technical_Data_Sheets/ TechnicalDataSheet_4043D_films_pdf.pdf.

[46] Husárová L, Pekařová S, Stloukal P, Kucharzcyk P, Verney V, Commereuc S, et al. Identification of important abiotic and biotic factors in the biodegradation of poly(l-lactic acid). International Journal of Biological Macromolecules. 2014;71(0):155-162. Special Issue: Biodegradable Biopolymers.

[47] Kaltoft P. Values about Nature in Organic Farming Practice and Knowledge. Sociologia Ruralis. 1999;39(1):39-53.

[48] Watson CA, Atkinson D, Gosling P, Jackson LR, Rayns FW. Managing soil fertility in organic farming systems. Soil Use and Management. 2002;18:239247.

[49] Stockdale EA, Shepherd MA, Fortune S, Cuttle SP. Soil fertility in organic farming systems - fundamentally different? Soil Use and Management. 2002;18:301-308.

[50] Levanon D, Pluda D. Chemical, Physical and Biological Criteria for Maturity in Composts for Organic Farming. Compost Science \& Utilization. 2002;10(4):339-346.

[51] Yeggi - Search Engine for 3D printable Models. Available from: http://www.yeggi.com/.

[52] Youngbuck. Triclaw Apple Picker. Available from: http://www.thingiverse.com/thing:146634/.

[53] Pearce JM. Open-source mobile water quality testing platform. Available from: http: //www.appropedia.org/Open-source_mobile_water_ quality_testing_platform.

[54] Gwamuri J. Chicken Feed Holder. Available from: http://www.appropedia.org/Chicken_Feed_Holder.

[55] Larsen S. Garden Hose Splitter. Available from: http: //www.appropedia.org/Garden_Hose_Splitter.

[56] 3Dponics - 3D Printing + Hydroponics. Available from: https://www.3dponics.com/.

[57] Clifford S. Custom Shovel Handle. Available from: http://www.appropedia.org/Custom_Shovel_Handle.

[58] Busack H. Sausage Funnels $70 \mathrm{~mm}$ for Meat Grinder. Available from: https://youmagine.com/ designs/sausage-funnels-70mm-for-meat-grinder.

[59] Finlay D. Ant Poison Trap Customizer. Available from: http://www.thingiverse.com/thing:148452.

[60] Pearce JM. Customizable Gasket. Available from: http://www.thingiverse.com/thing:58665.

[61] Alessi M. Hydroponic Halo Ring. Available from: http://www.appropedia.org/Hydroponic_halo_ring.

[62] Malinowski, Z. Hand Shovel. Available from: http: //www.appropedia.org/Hand_Shovel.

[63] Haupt B. Cassava Press. Available from: http://www. appropedia.org/Cassava_Press.

[64] Dubiel Z. Field Dressing Tool. Available from: http: //www.appropedia.org/Field_Dressing_Tool.

[65] Fuller TW. Contoured Spigot for 5-gallon buckets. Available from: http://www.appropedia.org/ Contoured_Spigot_for_5-gallon_buckets.
[66] Olliver, V. Hydroponic Plant Pot. Available from: http: //www.thingiverse.com/thing:16847.

[67] Wilder L. Pulleys. Available from: http://www. appropedia.org/Pulleys.

[68] Pearce JM. Corn sheller. Available from: http://www. appropedia.org/Corn_sheller.

[69] Dubiel Z. Gutting Tool. Available from: http://libre3d.com/category/569/Hand-Tools/listings/ 803/Gutting-Tool.html.

[70] Enigma B. Irrigation Stakes. Available from: http: //www.thingiverse.com/thing:26459.

[71] PiuLAB. Peristaltic Pump. Available from: http:// www.thingiverse.com/thing:414192.

[72] Open Source Hardware (OSHW) Definition 1.0. Available from: http://www.oshwa.org/definition/.

[73] Anzalone GC, Zhang C, Wijnen B, Sanders PG, Pearce JM. A Low-Cost Open-Source Metal 3-D Printer. IEEE Access. 2013;1:803-810.

[74] Haselhuhn AS, Gooding EJ, Glover AG, Anzalone GC, Wijnen B, Sanders PG, et al. Substrate Release Mechanisms for Gas Metal Arc Weld 3D Aluminum Metal Printing. 3D Printing and Additive Manufacturing. 2014;1(4):204-209.

[75] Wijnen B, Anzalone GC, Pearce JM. Open-source mobile water quality testing platform. Journal of Water, Sanitation and Hygiene for Development. 2014;4(3):532-537.

[76] Kreiger MA, Mulder ML, Glover AG, Pearce JM. Life cycle analysis of distributed recycling of postconsumer high density polyethylene for 3-D printing filament. Journal of Cleaner Production. 2014;70:90-96.

[77] Walters R. Laywood filament lets you 3D print with wood. Available from: http://www.geek.com/news/ laywood-filaments-lets-you-3d-print-with-wood$1517745 /$.

[78] 3ders.org. LAYBRICK: a new rough 3D printer filament for a sandstone effect. Available from: http: //www.3ders.org/articles/20130527-laybrick-a-newrough-3d-printer-filament-near-zero-warp.html.

[79] Formfutura. P3mm HIPS. Available from: http://www. formfutura.com/3mm-hips.html.

[80] Arevo - Perfecting the art of 3D printing. Available from: http://www.arevolabs.com/.

[81] Lock T. Think3dPrint3d: 3D printing with Acetal Filament. Available from: http://blog.think3dprint3d.com/ 2013/09/3d-printing-with-acetal-filament.html.

[82] Keytech S. Wants You to 3D Print Better, 3D Printing Industry. Available from: http: //3dprintingindustry.com/2014/09/10/keytech-wants3d-print-better-prototypes-new-filament-range/.

[83] World Bank. Energy - The Facts. Available from: http://go.worldbank.org/6ITD8WA1A0.

[84] Greene CR. U.S. organic farming emerges in the 1990s: adoption of certified systems. Washington, DC, USA: U.S. Department of Agriculture; 2001.

[85] Morêki JC. Village Poultry and Poverty Alleviation. 
In: Proceedings of the Workshop held in Mbabane: Community-based management of animal genetic resources. Swaziland; 2001. Available from: http: //www.fao.org/docrep/006/y3970e/y3970e0c4.htm.

[86] Segal Y. Prevention and control of poultry diseases for better farm profitability. In: FAO Document Repository;. Available from: http://www.fao. org/docrep/014/al875e/al875e00.pdf.

[87] Anzalone G, Pearce J, Wijnen B. Multi-Material Additive and Subtractive Prosumer Digital Fabrication with a Free and Open-source Convertible Delta RepRap. Rapid Prototyping. 2015; forthcoming.

[88] Ferrari GM. Build a gasket any size in silicone. Available from: http://www.thingiverse.com/thing:65470.

[89] Shrestha R, Gopalakrishnan C. Adoption and Diffusion of Drip Irrigation Technology: An Econometric Analysis. Economic Development and Cultural Change. 1993;41(2):407-418.

[90] IFOAM - International Federation of Organic Agriculture Movements. Principles of Organic Agriculture. Available from: http://www.ifoam.bio/en/ organic-landmarks/principles-organic-agriculture.

[91] Shinohara M, Aoyama C, Fujiwara K, Watanabe A, Ohmori $\mathrm{H}$, Uehara $\mathrm{Y}$, et al. Microbial mineralization of organic nitrogen into nitrate to allow the use of organic fertilizer in hydroponics. Soil Science and Plant Nutrition. 2011;57(2):190-203.

[92] Fujiwara K, Aoyama C, Takano M, Shinohara M. Suppression of Ralstonia solanacearum bacterial wilt disease by an organic hydroponic system. Journal of General Plant Pathology. 2012;78(3):217-220.

[93] Hydroponics: A practical guide for the soilless grower. London, UK: CRC Press; 2012.

[94] Gül A, Kıdoğlu F, Anaç D. Effect of nutrient sources on cucumber production in different substrates. Scientia Horticulturae. 2007;113(2):216-220.

[95] Atkin K, Nichols MA. ORGANIC HYDROPONICS. Acta Horticulturae. 2004;648:121-127.

[96] Shepherd M, Pearce B, Cormack B, Philipps L, Cuttle $S$, Bhogal $A$, et al. An assessment of the environmental impacts of organic farming. In: A review for DEFRA-funded Project OF0405; 2003. Available from: http://orgprints.org/6784/2/OF0405_909_TRP. pdf.

[97] Scialabba NEH, Müller-Lindenlauf M. Organic agriculture and climate change. Renewable Agriculture and Food Systems. 2010 6;25:158-169.

[98] Fuller RJ, Norton LR, Feber RE, Johnson PJ, Chamberlain DE, Joys AC, et al. Benefits of organic farming to biodiversity vary among taxa. Biology Letters. 2005;1(4):431-434.

[99] Hodgson JA, Kunin WE, Thomas CD, Benton TG, Gabriel D. Comparing organic farming and land sparing: optimizing yield and butterfly populations at a landscape scale. Ecology Letters. 2010;13(11):1358-1367.

[100] Gabriel D, Sait SM, Kunin WE, Benton TG. Food production vs. biodiversity: comparing organic and conventional agriculture. Journal of Applied Ecology. 2013;50(2):355-364.

[101] Kreiger M, Pearce JM. Environmental Life Cycle Analysis of Distributed Three-Dimensional Printing and Conventional Manufacturing of Polymer Products. ACS Sustainable Chemistry \& Engineering. 2013;1(12):1511-1519.

[102] Kreiger M, Pearce JM. Environmental Impacts of Distributed Manufacturing from 3-D Printing of Polymer Components and Products. In: Symposium D/G - Materials for Sustainable Development-Challenges and Opportunities. vol. 1492 of MRS Online Proceedings Library; 2013. p. 85-90. Available from: http://journals.cambridge.org/article S1946427413003199.

[103] Baechler C, DeVuono M, Pearce JM. Distributed recycling of waste polymer into RepRap feedstock. Rapid Prototyping Journal. 2013;19(2):118-125.

[104] Lyman H. Lyman Filament Extruder V4.1. Available from: http://www.thingiverse.com/thing:265375.

[105] Filastruder. Available from: http://www.filastruder. $\mathrm{com} /$.

[106] FilaFab. Available from: http://www.filafab.co.uk/.

[107] Filabot. Available from: http://www.filabot.com/.

[108] EWE Industries. Available from: http://www. eweindustries.com/.

[109] ExtrusionBot. Available from: http://www. extrusionbot.com/.

[110] Strooder. Omni Dynamics. Available from: http:// www.omnidynamics.co.uk/shop/strooder.

[111] Feeley SR, Wijnen B, Pearce JM. Evaluation of Potential Fair Trade Standards for an Ethical 3-D Printing Filament. Journal of Sustainable Development. 2014;7(5):1-12.

[112] Kreiger M, Anzalone GC, Mulder ML, Glover A, Pearce JM. Distributed Recycling of Post-Consumer Plastic Waste in Rural Areas. In: Symposium D/G - Materials for Sustainable Development-Challenges and Opportunities. vol. 1492 of MRS Online Proceedings Library; 2013. p. 91-96. Available from: http://journals.cambridge.org/article S1946427413002583.

[113] Kreiger MA, Mulder ML, Glover AG, Pearce JM. Life cycle analysis of distributed recycling of postconsumer high density polyethylene for 3-D printing filament. Journal of Cleaner Production. 2014;70:90-96.

[114] Rifkin J. The Zero Marginal Cost Society: The Internet of Things, the Collaborative Commons, and the Eclipse of Capitalism. London, UK: Palgrave Macmillan; 2014.

[115] Markillie P. A third industrial revolution. The Economist. 2012 Apr $21^{\text {st }}$;Special report: Manufacturing and innovation. Available from: http://www. economist.com/node/21552901.

[116] Godfray HCJ, Beddington JR, Crute IR, Haddad L, 
Lawrence D, Muir JF, et al. Food Security: The Challenge of Feeding 9 Billion People. Science. 2010;327(5967):812-818.

[117] Tomlinson I. Doubling food production to feed the 9 billion: A critical perspective on a key discourse of food security in the $\{U K\}$. Journal of Rural Studies. 2013;29:81-90. Food Security.

[118] Seufert V, Ramankutty N, Foley JA. Comparing the yields of organic and conventional agriculture. Nature. 2012;485(7397):229-232.

[119] Harper GC, Makatouni A. Consumer perception of organic food production and farm animal welfare. British Food Journal. 2002;104(3/4/5):287-299.

[120] Seyfang G. Ecological citizenship and sustainable consumption: Examining local organic food networks. Journal of Rural Studies. 2006;22(4):383395.

[121] Gil JM, Gracia A, Sánchez M. Market segmentation and willingness to pay for organic products in Spain. The International Food and Agribusiness Management Review. 2000;3(2):207-226.

[122] Goldman BJ, Clancy KL. A survey of organic produce purchases and related attitudes of food cooperative shoppers. American Journal of Alternative Agriculture. 1991 6;6:89-96.

[123] de Magistris T, Gracia A. The decision to buy organic food products in Southern Italy. British Food Journal. 2008;110(9):929-947.

[124] Scialabba N. Factors influencing organic agriculture policies with a focus on developing countries. In: Proceedings of the IFOAM Scientific Conference. Basel, Switzerland; 2000. p. 28-31.

[125] Setboonsarng S, Leung PS, Cai J. Contract farming and poverty reduction: the case of organic rice contract farming in Thailand. In: ADB Institute Discussion Paper No. 49; 2006. Available from: http://www.adbi.org/files/2006.05.dp49. pr.organic.farming.thailand.pdf.

[126] Pearce JM. The case for open source appropriate technology. Environment, Development and Sustainability. 2012;14(3):425-431.

[127] Zelenika I, Pearce JM. Innovation through collaboration: scaling up solutions for sustainable development. Environment, Development and Sustainability. 2014;16(6):1299-1316.

[128] All eyes on the sharing economy. The Economist. 2013 May $7^{\text {st }}$; The sharing economy. Available from: http://www.economist.com/news/technologyquarterly/21572914-collaborative-consumptiontechnology-makes-it-easier-people-rent-items.

[129] Hamari J, Sjöklint M, Ukkonen A. The Sharing Economy: Why People Participate in Collaborative Consumption. Social Science Research Network. 2015;Available from: http://papers.ssrn.com/ sol3/papers.cfm?abstract_id=2271971.

[130] Botsman R, Rogers R. What's Mine Is Yours: The Rise of Collaborative Consumption. HarperCollins; 2010.
[131] Leismann K, Schmitt $M$, Rohn $H$, Baedeker C. Collaborative Consumption: Towards a Resource-Saving Consumption Culture. Resources. 2013;2(3):184-203.

[132] Bauwens M. Toward a P2P Economy. In: Araya D, Peters MA, editors. Education in the Creative Economy: Knowledge and Learning in the Age of Innovation. Peter Lang; 2012. p. 305-330.

[133] Stalnaker S. Here comes the P2P Economy. Harvard Business Review. 2008 Feb 26 ${ }^{\text {st }}$;Available from: https://hbr.org/2008/02/here-comes-the-p2peconomy.

[134] Himanen P, Torvalds L. The Hacker Ethic: A Radical Approach to the Philosophy of Business. Random House Publishing Group; 2009.

[135] Shimoda M, Honda Ki. Insect reactions to light and its applications to pest management. Applied Entomology and Zoology. 2013;48(4):413-421.

[136] Copinet A, Bertrand C, Govindin S, Coma V, Couturier Y. Effects of ultraviolet light $(315 \mathrm{~nm})$, temperature and relative humidity on the degradation of polylactic acid plastic films. Chemosphere. 2004;55(5):763-773.

[137] Gijsman P, Meijers G, Vitarelli G. Comparison of the UV-degradation chemistry of polypropylene, polyethylene, polyamide 6 and polybutylene terephthalate. Polymer Degradation and Stability. 1999;65(3):433-441.

[138] King DL, Babasola A, Rozario J, Pearce JM. Mobile Open-Source Solar-Powered 3-D Printers for Distributed Manufacturing in Off-Grid Communities. Challenges in Sustainability. 2014;2(1):18-27.

[139] McDonough W, Braungart M. Cradle to cradle: Remaking the way we make things. MacMillan; 2010.

[140] Pearce J, Albritton S, Grant G, Steed G, Zelenika5 I. A new model for enabling innovation in appropriate technology for sustainable development. Sustainability: Science, Practice, \& Policy. 2012;8(2):42-53.

[141] Swan M. Crowdsourced Health Research Studies: An Important Emerging Complement to Clinical Trials in the Public Health Research Ecosystem. Journal of Medical Internet Research. 2012;14(2):e46.

[142] Prestopnik NR, Crowston K. Gaming for (citizen) science: Exploring motivation and data quality in the context of crowdsourced science through the design and evaluation of a social-computational system. In: "Computing for Citizen Science" workshop at the IEEE eScience Conference. Stockholm, Sweden; 2011. Available from: http://crowston.syr.edu/ system/files/gamingforcitizenscience_ver6.pdf.

[143] Prestopnik NR, Crowston K. Citizen science system assemblages: Understanding the technologies that support crowdsourced science. In: iConference 2012. Toronto, Ontario; 2012. Available from: http://crowston.syr.edu/sites/crowston. syr.edu/files/citizensciencesystemassemblage.pdf.

[144] Olliver V. Decoy Butterfly. Available from: http://www. thingiverse.com/thing:6685. 